Disclosure Statement: S. Wang receives grant support from (\#). R. Greene has nothing to disclose.

\title{
Neurologic Changes and Depression
}

\author{
Ryan D. Greene, Psy D ${ }^{\mathrm{a}, \mathrm{b}, *}$, Sophia Wang, MD ${ }^{\mathrm{a}, \mathrm{b}, \mathrm{c}, \mathrm{d}}$ \\ ${ }^{a}$ Richard L. Roudebush VAMC, 1481 W. 10th Street, Indianapolis, IN 46202, USA \\ ${ }^{b}$ Department of Pyschiatry, Indiana University School of Medicine, Goodman Campbell Neuroscience \\ Center, 355 W. 16th Street, Indianapolis, IN 46202, USA \\ ${ }^{c}$ Center of Health Innovation and Implementation Science, Center for Translational Science and Innovation, \\ Indianapolis, IN, USA \\ ${ }^{\mathrm{d} S}$ Sandra Eskenazi Center for Brain Care Innovation, Eskenazi Hospital, Indianapolis, IN, USA \\ * Corresponding author. rygreene@iupui.edu
}

\begin{abstract}
This article covers current research on the relationship between depression and cognitive impairment in older adults. First, it approaches the clinical assessment of late-life depression and comorbid cognitive impairment. Cognitive risk factors for suicide are discussed. Research is then provided on neuropsychological changes associated with depression, discussing subjective cognitive impairment, mild cognitive impairment, and dementia profiles. Additionally, literature regarding neuroimaging and biomarker findings in depressed older adults is presented. Finally, therapeutic models for treatment of late-life depression are also discussed, including psychotherapy models, holistic treatments, pharmacologic approaches, and brain-stimulation therapies.
\end{abstract}

Keywords: Major depressive disorder; Subjective cognitive impairment; Mild cognitive impairment; Neurocognitive disorder; Neuropsychological testing; Neuroimaging; Psychotherapy; Antidepressants

\section{KEY POINTS}

- The assessment of late-life depression with comorbid cognitive impairment can be challenging and requires a clear clinical history and a thorough medical and cognitive assessment.

- There are several neuropsychological changes associated with late-life depression, ranging from subjective cognitive complaints to mild cognitive impairment to dementia.

- Changes on neuroimaging and in several biomarkers (eg, apolipoprotein E e4 allele, betaamyloid, tau, neurotrophins, and so forth) have been associated with late-life depression.

- Multiple psychotherapeutic techniques have been found effective in the treatment of latelife depression as well as holistic/nontraditional, pharmacologic, and brain-stimulation approaches.

This is the author's manuscript of the article published in final edited form as:

Greene, R. D., \& Wang, S. (2018). Neurologic Changes and Depression. The Psychiatric Clinics of North America, 41(1), 111-126. https://doi.org/10.1016/j.psc.2017.10.009 


\section{INTRODUCTION}

Late-life depression affects 3.0\% to $4.5 \%$ adults older than 65 years in the United States. ${ }^{1}$ For many older adults with depression, affective symptoms are accompanied by cognitive difficulties, which can range from subjective cognitive complaints to mild cognitive impairment (MCI) to dementia. Epidemiologic findings suggest that late-life depression may be a risk factor for dementia. ${ }^{2,3}$ Given the relatively high prevalence of depression in older adults and a growing focus on modifiable risk factors for dementia, there is interest in better understanding the complex relationship between depression and cognitive impairment. This review focuses on individuals with unipolar depression without psychotic features with comorbid MCI or dementia. To align with the terminology used in earlier literature and within the International Classification of Diseases, Tenth Revision coding system, the authors use Diagnostic and Statistical Manual of Mental Disorder (Fourth Edition, Text Revision) (DSM-IV TR) terminology (ie, MCI and dementia) instead of the DSM-5 terminology for neurocognitive disorders.

\section{Clinical Assessment of Late-Life Depression with Comorbid Cognitive Impairment}

Accurately diagnosing late-life depression can be challenging because of the wide variety of symptom presentations. ${ }^{4} \mathrm{~A}$ few key points can guide the clinical evaluation of depression in older adults with comorbid cognitive impairment. Specifically, these are (1) receiving a detailed history from both the patients and their informants, (2) following patients longitudinally to monitor symptom progression, and (3) interviewing with potential reversible causes of cognitive impairment in mind (eg, substance use, metabolic problems, and so forth).

First, the most powerful diagnostic tool the clinician has is the clinical interview. Obtaining a detailed history from both the patients and their informants will be a critical piece to determine whether the patients have a primary mood and/or cognitive disorder. In certain cases, a detailed neuropsychological evaluation may be necessary to delineate cognitive and mood symptoms. Furthermore, neuropsychological testing is indicated when there are questions of multiple comorbidities, questionable self- or informant-report, and to establish a baseline in mild dementia and MCI cases. An accurate informant can be especially helpful, as many patients frequently experience anosognosia (lack of awareness due to neurologic disease) about their cognitive deficits or alexithymia (inability to describe one's feelings). Patients may also experience variations in their mood depending on the time of day (ie, diurnal variations); therefore, an informant may be helpful in mapping the overall mood.

Second, clinicians can follow patients' symptoms over time. This technique can be important in the diagnosis of more complex cases when it is difficult to determine whether patients' have primary cognitive disorder, primary mood disorder, or both. Clinicians should determine whether emotional and cognitive symptoms resolve, remain static, or progress over time. For example, if the cognitive symptoms worsen despite stable or improved mood, this would suggest a primary cognitive disorder. Alternatively, if the cognitive symptoms vary with emotional state, for example, worsening with increased emotional distress, this would suggest a primary mood disorder.

When patients present with both significant emotional and cognitive complaints, clinicians should aggressively treat the depressive symptoms first and then reassess cognitive 
symptoms after some resolution of the severe emotional distress. Literature has indicated that mild to moderate depression is best treated with a combination of antidepressants and psychotherapy. ${ }^{5}$ However, the patients' cognitive capacity to engage in psychotherapy should always be considered. Electroconvulsive therapy (ECT) and other brain-stimulation therapies are generally reserved for severe or treatment-resistant cases.

Third, clinicians should always approach these complex cases considering potential reversible causes of the patients' mood and cognitive symptoms. One of the most overlooked, but easily reversible, causes of cognitive impairment in older adults is medication side effects. Specifically, research has shown that benzodiazepines, anticholinergics, opiates, non-narcotic pain medications (ie, tramadol), hypnotics, and antipsychotics have been associated with cognitive symptoms. ${ }^{6}$ Substance use in older adults is frequently not explored thoroughly, particularly in regard to alcohol and cannabis use. ${ }^{7}$ Finally, a thorough workup for late-life depression should also include a comprehensive laboratory workup, assessing hematologic, metabolic, toxic, and infectious contributions to cognitive and/or affective symptoms.

\section{Risk Factors}

The interactions between medical illnesses, depression, and cognitive impairments are typically multidirectional, making it difficult to distinguish causes of current symptom presentations. Men, Caucasians, and individuals with functional impairments were more likely to present with affective symptoms of depression in MCI and early Alzheimer disease (AD). ${ }^{8}$ Cerebrovascular disease has been associated with both late-life depression and comorbid executive dysfunction. ${ }^{9,10}$ Cognition and mood can also be impacted by other causes of organ failure, including chronic renal failure ${ }^{11,12}$ and chronic obstructive pulmonary disease. ${ }^{13,14}$

\section{SUICIDE AND COGNITION}

The incidence of suicide among individuals aged 85 years and older in the United States is 17.8 deaths per 100,000 (compared with 15.0 deaths per 100,000 for those aged $65-84$ years). ${ }^{15}$ Although aging alone may increase the suicide risk, further research is needed to clarify the relationship between cognitive changes from aging and suicidality. The ventromedial prefrontal cortices, which are important in reasoning and decision-making, may become impaired in later adulthood $^{16}$ and consequently increase the risk for suicidality. This impairment may be further exacerbated by changes in social support, that is, depressed elders with suicide attempts tend to have greater difficulties socially. ${ }^{17}$ Finally, many medical illnesses affecting older adults are often accompanied by comorbid depression and cognitive impairments, likely predisposing the affected older adult to suicidality. ${ }^{11,18,19}$

\section{NEUROPSYCHOLOGICAL CHANGES IN DEPRESSION}

\section{Cognitive Aging}

Cognitive aging is characterized by gradual changes in cognitive functioning associated with normal aging. ${ }^{20}$ These changes can be variable between patients, are not secondary to a neurodegenerative illness or typically accompanied by functional decline, and generally accelerate in late life. Specific cognitive changes associated with aging include trouble with memory recall and executive dysfunction and slowed processing speed. In contrast, visuospatial skills, crystallized intelligence, and vocabulary knowledge remain stable. ${ }^{21}$ Generally, good management of multiple health factors, including hypertension, diabetes, chronic obstructive pulmonary disease, and so forth, and psychiatric disorders (including depression and anxiety) can help mitigate some of the changes associated with normal aging. 


\section{Subjective Cognitive Impairment and Depression}

Subjective cognitive impairment (SCI) refers to the perception of cognitive decline without evidence of deficits on objective measures. ${ }^{22}$ Several cross-sectional studies on the relationship between subjective cognitive complaints and objective impairments on cognitive testing have shown conflicting findings, ranging from a positive correlation ${ }^{23-25}$ to no association. ${ }^{26}$ However, in longitudinal studies, subjective cognitive impairments have been associated with higher rates of incident cognitive impairment and dementia. ${ }^{22,27-29}$ Of note, multiple studies have shown that subjective cognitive impairments are common in individuals with late-life depression, with ranges falling from $50 \%$ to $70 \%{ }^{30,31}$ Interestingly, one prospective study showed that tau-mediated degeneration, but not beta-amyloid (A $\beta$ ) deposition, was significantly higher in patients with MCI compared with SCI. ${ }^{32}$ At this time, although there seems to be compelling evidence of a relationship between SCI and depression, further research is needed to more fully understand the causal relationship between the two.

\section{Mild Cognitive Impairment and Depression}

MCI is characterized by cognitive complaints (per the patients, informants, or observed by a clinician), objective evidence of impairment, independence in functional abilities, and no impairment in social or occupational functioning. ${ }^{33}$ The prevalence of depression in MCI varies widely, with population-based estimates ranging from $3.0 \%$ to $83.0 \%$, with a median prevalence of $44.3 \%$; alternatively, the prevalence of $\mathrm{MCI}$ in depression ranges from $30 \%$ to $50 \%$. ${ }^{34-36}$ For most individuals with late-life depression and comorbid cognitive impairment, the profile seems to be a dys-executive pattern ${ }^{37}$ characterized by difficulties with working memory, set-shifting, planning, and response inhibition. This syndrome suggests that cerebrovascular disease affects white matter tracts in the fronto-striatal pathways, resulting in executive dysfunction and, potentially, the affective symptoms of depression. Additionally, studies have found that late-life depression is associated with a higher ischemic burden on structural MRI as well as impaired executive and memory functions. ${ }^{38,39}$

\section{Dementia and Depression}

Longitudinal studies have provided information on the cognitive trajectories of those with late-life depression. Potter and colleagues ${ }^{40}$ found that baseline impairments in encoding and executive functioning in patients with depression seem to be risk factors for progression to dementia. However, this progression seems to be highly variable. Steffens and colleagues ${ }^{41}$ found that in a large group of nondemented depressed older adults, at the 2-year follow-up approximately $25 \%$ had reverted back to normal cognitive functioning, $15 \%$ had progressed to dementia, and the remainder continued to display cognitive impairments without functional decline. Additional research has shown that although one would expect most individuals with late-life depression and MCI to progress to a vascular dementia, these vascular risk factors may simply serve to accelerate the AD process. ${ }^{34,42}$

\section{BIOMARKERS}

\section{Apolipoprotein E, Beta-Amyloid, and Tau}

Studies on various markers in neurodegenerative illnesses (ie, apolipoprotein E $\varepsilon 4$ variant [APOE \&4], A $\beta$, and tau) and late-life depression have been variable. Regarding APOE $\varepsilon 4$, there seems to be a significant relationship between depressive symptoms and APOE $\varepsilon 4$ in regard to progression from MCI to dementia. Specifically, a longitudinal study showed that APOE $\varepsilon 4$ 
carriers with depression were 4.4 times more likely to progress to AD compared with non-APOE $\varepsilon 4$ carriers with depression. ${ }^{43}$ Meanwhile, a cross-sectional study found no relationship between $A P O E \& 4$ status, depression, and cognition. ${ }^{44}$ Further research on the relation between $\mathrm{A} \beta$ and $A P O E \varepsilon 4$ is mixed. ${ }^{45-48}$ Finally, although the relationship between tau protein and late-life depression has not yet been clearly established, a longitudinal study indicated those with late-life depression and elevated cerebrospinal fluid total tau levels progressed differently from MCI to AD. ${ }^{49,50}$

\section{Neurotrophins}

Recent literature has indicated that individuals with late-life depression display a reduction of neurotrophins, including nerve growth factor, glial-derived neurotrophic factor, and brain-derived neurotrophic factor. ${ }^{51-53}$ However, Arnold and colleagues ${ }^{54}$ found that 2 neurotrophins specifically associated with neurogenesis, long-term potentiation, and response to ischemic injuries seemed to be increased in older adults with depressive symptoms: vascular endothelial growth factor and hepatocyte growth factor (reflecting possible compensatory responses).

\section{Hippocampal-Pituitary-Adrenal Axis, Insulin Pathway, and Inflammation}

There is limited evidence suggesting that the hippocampal-pituitary-adrenal (HPA) axis and inflammation play a role in late-life depression with comorbid cognitive deficits. Although chronic distress has been associated with disruption in the HPA axis, research on this relationship with comorbid cognitive impairments has been variable. ${ }^{54,55}$ Interestingly, literature has provided compelling evidence of hippocampal atrophy in individuals with severe depression and positive inflammation biomarkers. ${ }^{56}$

\section{NEUROIMAGING AND ELECTROPHYSIOLOGY}

\section{Structural MRI}

With structural MRI, changes in both white and gray matter have been associated with late-life depression and comorbid cognitive impairment compared with nondepressed older adults. In support of the vascular hypothesis, suggesting that cerebrovascular disease is a major contributor to late-life depression, longitudinal MRI studies have shown a correlation between the severity of depression and white matter ischemic changes. ${ }^{57,58}$ Similarly, these white matter lesions, especially when concentrated in anterior periventricular regions, have been associated with comorbid executive dysfunction.

Gray matter changes seen in late-life depression may be part of the prodrome to AD. Hippocampal atrophy, a well-known feature of $\mathrm{AD}$, has also been shown to be associated with a higher severity of emotional distress in nondemented individuals. ${ }^{59}$ For individuals with MCI, depression was associated with reduced thickness of the entorhinal cortex, anterior cingulate cortex, and bilateral dorsomedial and ventromedial prefrontal cortices. ${ }^{60-62}$

\section{Functional MRI}

The connectome (how the brain functions as a system of multiple connected networks) and how pathophysiologic processes can disrupt the connectome are now major areas of research. Recent functional MRI studies suggest that structural lesions associated with late-life depression can also lead to the disruption of networks associated with the clinical features in late-life depression (eg, apathy and executive dysfunction). In one study, the cognitive control network 
and corticostriatal networks were shown to be linked to cognitive dysfunction (ie, executive impairments) in late-life depression. ${ }^{63}$

\section{PET Imaging and Florbetapir Imaging}

PET imaging studies provide conflicting information. Specifically, one study found that some patients with late-life depression and MCI showed a Pittsburgh compound B imaging pattern suggestive of $\mathrm{AD},{ }^{64}$ whereas another did not replicate this relationship. ${ }^{65}$ Research with an amyloid and neurofibrillary tangle binding agent (FDDNP) for individuals with MCI and depression found variable temporal and parietal lobe binding. ${ }^{66,67}$ This finding was further confirmed by research coming from the Alzheimer's Disease Neuroimaging Initiative showing that lifelong depressive symptoms reliably predicted $\mathrm{A} \beta$ accumulation in patients with MCI. ${ }^{68}$ These findings suggest that larger studies are needed to understand the complex PET imaging relationship between depression and cognitive impairment.

\section{Electrophysiology Markers}

Using electroencephalogram (EEG) technology, individuals with late-life depression have shown more slow-wave activity and prolonged $\mathrm{P} 300_{\mathrm{a}}$ latencies, indicating decreased cerebral arousal and information processing. ${ }^{69}$ Additional researching using a complex response inhibition task showed decreased event potential localized to the anterior cingulate cortex in depressed older adults. ${ }^{70}$ Although not diagnostic, these EEG findings may help shed light on the cognitive deficits often reported by individuals with late-life depression.

\section{PSYCHOTHERAPIES}

Several evidence-based psychotherapies have been shown to be effective in the treatment of late-life depression, even in those with associated cognitive impairments. Psychotherapy should always be considered for individuals with MCI and early AD, especially, as older adults typically only show an adequate response in approximately $30 \%$ after a trial of a first-line antidepressant. ${ }^{71}$

\section{Cognitive Behavioral Therapy}

Cognitive-behavioral therapy (CBT) has become one of the more common treatments for a wide-range of disorders, including depression, posttraumatic stress disorder, anxiety, insomnia, and so forth. It is based on the assumption that maladaptive patterns of thought and behavior contribute to the development of emotional distress, such as depression. CBT focuses on breaking the links between dysfunctional cognitions, emotions, and behaviors. One recent meta-analysis ${ }^{72}$ found that CBT and problem-solving therapy (PST) were more effective than other therapies in treating late-life depression. Furthermore, research has shown CBT to be effective even when applied to individuals with MCI. $^{73}$

\section{Interpersonal Therapy}

Interpersonal therapy (IPT) concludes that the development of depressive symptoms is influenced by the relationships between patients and their significant others. For treatment, it combines techniques from supportive and psychodynamic therapies, focusing on interactions between the therapists and the patients, with the goal of generalizing positive interactions toward the patients' significant others. IPT has been shown to be effective in the treatment of treatmentresistant depression for younger to middle-aged adults, ${ }^{74}$ although there are fewer studies in older adults. One study ${ }^{75}$ showed that IPT, when modified to include patients' caregivers, was effective in reducing depressive symptoms in cognitively impaired individuals. 


\section{Problem-Solving Therapy}

PST focuses treatment on everyday problems, with the goal of improving coping skills to prevent distress. The therapists work with the patients to identify problems, develop a set of possible solutions, decide on one of these solutions, and then implement the solution (assessing its success). Two meta-analyses ${ }^{76,77}$ have shown that PST effectively treats late-life depression. Furthermore, these findings are supported by another meta-analysis indicating PST was more effective than several other psychotherapies. ${ }^{72}$ In a multisite clinical trial of older adults with depression and executive dysfunction, problem-solving was shown to be more effective than supportive therapy in reducing depressive symptoms (persisting long after the 12 weeks of treatment) ${ }^{78}$ Furthermore, late-life depression seems responsive to modified PSTs, including primary care-based PST, problem adaptation therapy, and home-bound PST for individual with cognitive impairments. ${ }^{79-81}$

\section{Reminiscence and Life Review}

Based on Erikson's last stage of life span development focused on "meaning making," reminiscence and life review therapies were designed to treat psychological disorders in older adults. The life review is a systematic process structured around life themes, such as one's childhood, parenthood, work productivity, and so forth. For treatment, the therapists work with the patients to recall memories with the goal of focusing on positive life events and enhancing well-being. The life review process then focuses on developing a narrative of the person's life, evaluating events and reframing and integrating them. There are 3 meta-analyses that have shown reminiscence and life review therapies to be effective in treating late-life depression ${ }^{72,82,83}$; however, these data were complicated by the variations in how these therapies are applied.

\section{HOLISTIC AND OTHER NONTRADITIONAL APPROACHES}

Because of a variety of reasons, for many older adults, holistic and other nontraditional approaches for treatment of depression may be more acceptable than psychopharmacologic and psychotherapeutic approaches. First, as nontraditional treatments (eg, physical activity, art therapy, meditation, and so forth) have been used by many for non-mental health reasons, older adults may be more open to their use, especially if they have no history of psychiatric treatment. Second, older adults may find it easier to speak with their physicians about their physical symptoms than their emotional or cognitive complaints. Therefore, offering holistic and nontraditional treatments, which may benefit both physical and mental health, may be more acceptable. Third, as the mental health community has grown in the integration and study of nontraditional treatments, the authors have found that, although not easy to study, these approaches may offer unique benefits for the treatment of late-life depression. ${ }^{84}$

\section{Physical Activity and Cognitive Training}

Physical exercise has been shown to have a significant impact on both late-life depression and cognition. A systematic review by Mura and Carta ${ }^{85}$ showed that most of the included studies showed reductions in depressive symptoms (with no other interventions used). Multiple studies have shown that exercise alone is equally effective, if not a powerful addition, to antidepressant medications. ${ }^{86-88}$ Moreover, exercise has the potential to improve cognitive functioning in older adults as well. Particularly, executive functions, for example, planning, working memory, problem-solving, and so forth, seem to have robust benefits from aerobic exercise. ${ }^{89}$ 
There also seems to be some evidence that cognitive training may have some cognitive benefits in depressed older adults. ${ }^{90,91}$ However, further research needs to be done to examine generalization from these effects to daily functioning.

\section{Technological Interventions}

Recent advances have allowed technological approaches to be combined with traditional treatments of mental health issues. Internet-based psychotherapies ${ }^{92}$ and exergaming ${ }^{93}$ can function independently or be further augmented with the use of mobile applications. ${ }^{94}$ However, there is not yet compelling evidence for the effectiveness of these approaches with older adults.

\section{Religion and Spirituality}

With the increased importance of cultural competency in mental health research, the role of religious and spirituality practices has gained recognition for the treatment of late-life depression. For example, studies on the use of yoga and meditation have shown significant reductions in depressive symptoms in older adults. ${ }^{95,96}$ However, the effects these practices have on cognition are not yet well known. Finally, research on the use of tai chi with older adults suggests improvements in depressive symptoms, physical functioning, and cognitive functioning as well as reductions in inflammatory C-reactive protein. ${ }^{97,98}$

\section{Music, Art, and Dance Therapy}

Various art therapies have been shown to have positive effects on both mood and cognition. Specifically, music therapy may improve depression and cognitive symptoms in older adults ${ }^{99,100}$ and dance therapy has shown a significant effect on mood. ${ }^{101,102}$

\section{Ketamine}

Recent literature has indicated that ketamine, typically used as an intravenous anesthetic, has been shown to have rapid antidepressant efficacy in individuals with refractory major depressive disorder (MDD). ${ }^{103}$ Moreover, initial studies have not shown there to be lasting neurocognitive deficits secondary to ketamine treatment 1 week after administration, although there is an initial slowing in processing speed. ${ }^{104}$

\section{PHARMACOLOGIC APPROACHES}

\section{Antidepressants}

Most of the recent literature on depression and cognition has focused on selective serotonin reuptake inhibitors (SSRIs) and selective serotonin-norepinephrine reuptake inhibitors (SNRIs). The results on SSRIs have been variable, depending largely on the medication being studied. Specifically, sertraline was indicated to improve episodic memory and executive functions, ${ }^{9}$ whereas citalopram was shown to cause difficulties in response inhibition, verbal learning, and processing speed. ${ }^{105,106}$ Alternatively, there seems to be more compelling evidence of cognitive benefits from SNRIs. ${ }^{107,108}$ Alternatively, antidepressants with anticholinergic effects (ie, many tricyclic antidepressants) likely have detrimental effects on cognition. ${ }^{109}$

\section{Cholinesterase Inhibitors and N-Methyl-D-Aspartate Antagonists}

Research on the use of cholinesterase inhibitors for late-life depression and comorbid MCI are limited, with conflicting findings in terms of cognitive and mood outcomes. Interestingly, 
research on donepezil has shown varying results, from positive effects on depression ${ }^{110,111}$ to no positive effects. ${ }^{12}$ Memantine, an N-methyl-D-aspartate antagonist, has not been shown to have any efficacy as a treatment of comorbid MDD. ${ }^{113-115}$

\section{BRAIN STIMULATION THERAPIES}

\section{Electroconvulsive Therapy}

Although initially developed for the treatment of psychotic symptoms, ECT has been shown to be effective in the treatment of severe, treatment-resistant depression. ${ }^{116}$ Although not fully understood, ECT is thought to release multiple neurotransmitters, including glutamate, noradrenalin, dopamine, and serotonin. ${ }^{117,118}$ However, post-ECT cognitive adverse effects have been found. These effects tend to be time limited and include disorientation after each ECT session and both anterograde and retrograde amnesia, which can persist for 1 to 6 months after the last session. ${ }^{17,119}$ More subtle cognitive deficits have also been shown to be time limited and include decreases in processing speed, working memory, learning and memory, and executive functions. ${ }^{120,121}$

\section{Other Brain-Stimulation Therapies}

Rather than using an electrical current, transcranial magnetic stimulation (TMS) uses an electromagnet to stimulate brain regions. In one study, patients receiving repetitive TMS showed improvement in depressive symptoms, functioning, and cognitive performances. ${ }^{122-124}$ Although not yet used to study late-life depression with comorbid depression, this intervention seems to be a promising area of future research.

Although deep brain stimulation (DBS) has been shown to be associated with successful outcomes for treatment-resistant depression, responses differ among studies, with 6-month success rates ranging from $41 \%$ to $66 \%{ }^{125-128}$ Several DBS targets have been studied, including the subgenual cingulate region, subcallosal tracts, nucleus accumbens, ventral striatum, inferior thalamic peduncle, and habenula. At this time, there is not compelling evidence for cognitive benefits of DBS for patients with late-life depression and comorbid cognitive impairment.

\section{SUMMARY}

Although the understanding of the relationship between depression and cognition has grown significantly over the past several years, researchers continue to uncover more details regarding the complex interplay between these two factors. There have been several promising developments recently, especially with advances in neuroimaging and biomarker research. Additionally, although several therapeutic modalities have been researched for the treatment of late-life depression, many of them have been limited by factors, including providers' experience and/or treatment availability. Given the current literature, optimal assessment and treatment of older adults with depression should include multiple modalities, such as neuroimaging, genotyping, and risk factor burden calculations, to better understand the patients' prognosis and potential treatment response. Future research should then focus on more individualized treatments, pharmacologic and psychotherapeutic, for late-life depression in order to more effectively treat both cognitive and affective symptoms.

\section{ACKNOWLEDGMENTS}

The authors thank Dr Fred Unverzagt for his irreplaceable expertise in this field and his valuable contributions to this body of work. 


\section{REFERENCES}

1. Eden J, LeM, Maslow K, et al, editors. The mental health and substance use workforce for older adults: in whose hands? Washington, DC: Natl. Acad. Press; 2012.

2. Byers AL, Yaffe K. Depression and risk of developing dementia. Nat Rev Neurol 2011;7:32331.

3. Steenland K, Karnes C, Seals R, et al. Late-life depression as a risk factor for mild cognitive impairment or Alzheimer's disease in 30 US Alzheimer's disease centers. J Alzheimers Dis 2012;31:265-75.

4. Blazer D. Depression in late life: review and commentary. J Gerontol A Biol Sci Med Sci 2003;58(3):249-65.

5. Karyotaki E, Smit Y, Holdt Henningsen K, et al. Combining pharmacotherapy and psychotherapy or monotherapy for major depression? A meta-analysis on the long-term effects. J Affect Disord 2016;194:144-52.

6. Islam MM, Iqbal U, Walther B, et al. Benzodiazepine use and rick of dementia in the elderly population: a systematic review and meta-analysis. Neuroepidemiology 2016;47(3-4):181-91.

7. Blank K. Older adults \& substance use: new data highlight concerns. SAMHSA News, JanFeb. 2009. Available at: http://www.samhsa.gov/. Accessed June 12, 2017.

8. Apostolova LG, Di LJ, Duffy EL, et al. Risk factors for behavioral abnormalities in mild cognitive impairment and mild Alzheimer's disease. Dement Geriatr Cogn Disord 2014;37:31526.

9. Barch DM, D' Angelo G, Pieper C, et al. Cognitive improvement following treatment in latelife depression: relationship to vascular risk and age of onset. Am J Geriatr Psychiatry 2012;20:682-90.

10. Sheline YI, Pieper CF, Wlesh-Bohmer K, et al. Support for the vascular depression hypothesis in late-life depression: results of a 2-site, prospective, antidepressant treatment trial. Arch Gen Psychiatry 2010;67(3):277-85.

11. Agganis BT, Weiner DE, Giang LM, et al. Depression and cognitive function in maintenance hemodialysis patients. Am J Kidney Dis 2010;56:704-12.

12. Elias MF, Dore GA, Davey A. Kidney disease and cognitive function. Contrib Nephrol 2013;179:42-57.

13. Doyle T, Palmer S, Johnson J, et al. Association of anxiety and depression with pulmonaryspecific symptoms in chronic obstructive pulmonary disease. Int J Psychiatry Med 2013;45:189202.

14. Bratek A, Zawada K, Beil-Gawelczyk J, et al. Depressiveness, symptoms of anxiety and cognitive dysfunctions in patients with asthma and chronic obstructive pulmonary disease 
(COPD): possible associations with inflammation markers: a pilot study. J Neural Trans (Vienna) 2015;122:S83-91.

15. Am Found Suicide Prev. Facts and figures. New York: Am. Found. Suicide Prev; 2012. Available at. https://www.afsp.org/understanding-suicide/facts-and-figures.

16. Conwell Y, Van Orden K, Caine ED. Suicide in older adults. Psychiatr Clin N Am 2011;34:451-68.

17. Szanto K, Dombrovski AY, Sahakian BJ, et al. Social emotion recognition, social functioning, and attempted suicide in late-life depression. Am J Geriatr Psychiatry 2012;20:25765 .

18. Chan SS, Lyness JM, Conwell Y. Do cerebrovascular risk factors confer risk for suicide in later life? A case-control study. Am J Geriatr Psychiatry 2007;15: 541-4.

19. Kurella M, Kimmel PL, Young BS, et al. Suicide in the United States end-stage renal disease program. J Am Soc Nephrol 2005;16:774-81.

20. Blazer DG, Wallace RB. Cognitive aging: what every geriatric psychiatrist should know. J Geriatr Psychiatry 2016;24:776-81.

21. Harada CN, Natelson Love MC, Triebel KL. Normal cognitive aging. Clin Geriatr Med 2013;29(4):737-52.

22. Hill NL, Mogle J, Wion R, et al. Subjective cognitive impairment and affective symptoms: a systematic review. J Gerontologist 2016;56(6):e109-27.

23. Amariglio RE, Townsend MK, Grodstein F, et al. Specific subjective memory complaints in older persons may indicate poor cognitive function. J Am Geriatr Soc 2011;59(9):1612-7.

24. Jonker C, Launer LJ, Hooijer C, et al. Memory complaints and memory impairment in older individuals. J Am Geriatr Soc 1996;44(1):44-9.

25. Montejo Carrasco P, Montenegro-Pena M, Lopez-Higes R, et al. Subjective memory complaints in healthy older adults: fewer complaints associated with depression and perceived health, more complaints also associated with lower memory performance. Arch Gerontol Geriatr 2017;70:28-37.

26. Minett TS, Da Silva RV, Ortiz KZ, et al. Subjective memory complaints in an elderly sample: a cross sectional study. Int J Geriatr Psychiatry 2008;23(1): 49-54.

27. Dufouil C, Fuhrer R, Alperovitch A. Subjective cognitive complaints and cognitive decline: consequence or predictor? The epidemiology of vascular aging study. J Am Geriatr Soc 2005;53(4):616-21.

28. Waldorff FB, Siersma V, Vogel A, et al. Subjective memory complaints in general practice predicts future dementia: a 4-year follow-up study. Int J Geriatr Psychiatry 2012;27(11):1180-8.

29. Wang S, Blazer DG. Depression and cognition in the elderly. Annu Rev Clin Psychol $2015 ; 11: 331-60$. 
30. Bartley M, Bokde AL, Ewers M, et al. Subjective memory complaints in community dwelling healthy older people: the influence of brain and psychopathology. Int. J Geriatr Psychiatry 2012;27(8):836-43.

31. Chu CS, Sun IW, Begum A, et al. The association between subjective memory complaint and objective cognitive function in older people with previous major depression. PLoS One 2017;12(3):e0173027.

32. Wolfsgruber S, Polcher A, Koppara A, et al. Cerebrospinal fluid biomarkers and clinical progression in patients with subjective cognitive decline and mild cognitive impairment. J Alzheimers Dis 2017;58(3):939-50.

33. Langa KM, Levine DA. The diagnosis and management of mild cognitive impairment: a clinical review. JAMA 2014;312(23):2551-61.

34. Bhalla RK, Butters MA, Becker JT, et al. Patterns of mild cognitive impairment after treatment of depression in the elderly. Am J Geriatr Psychiatry 2009;17: 308-16.

35. Reinlieb M, Ercoli LM, Siddarth P, et al. The patterns of cognitive and functional impairment in amnestic and non-amnestic mild cognitive impairment in geriatric depression. Am J Geriatr Psychiatry 2014;22:1487-95.

36. Yeh YC, Tsang HY, Lin PY, et al. Subtypes of mild cognitive impairment among the elderly with major depressive disorder in remission. Am J Geriatr Psychiatry 2011;19:923-31.

37. Morimoto SS, Alexopoulos GS. Cognitive deficits in geriatric depression: clinical correlates and implications for current and future treatment. Psychiatr Clin N Am 2013;36:517-31.

38. Mackin RS, Nelson JC, Delucchi KL, et al. Association of age at depression onset with cognitive functioning in individuals with late-life depression and executive dysfunction. Am J Geriatr Psychiatry 2014;22:1633-41.

39. Salloway S, Malloy P, Kohn R, et al. MRI and neuropsychological differences in early- and late-life-onset geriatric depression. Neurology 1996;46:1567-74.

40. Potter GG, Wagner HR, Burke JR, et al. Neuropsychological predictors of dementia in latelife major depressive disorder. Am J Geriatr Psychiatry 2013;21: 297-306.

41. Steffens DC, McQuoid DR, Potter GG. Outcomes of older cognitively impaired individuals with current and past depression in the NCODE study. J Geriatr Psychiatry Neurol 2009;22:5261.

42. Koenig AM, Bhalla RK, Meryl AB. Cognitive functioning and late-life depression. J Int Neuropsychol Soc 2014;20:1-7.

43. Irie F, Masaki KH, Petrovitch H, et al. Apolipoprotein E epsilon4 allele genotype and the effect of depressive symptoms on the risk of dementia in men: the Honolulu-Asia aging study. Arch Gen Psychiatry 2008;65:906-12. 
44. Bogner HR, Richie MB, de Vries HF, et al. Depression, cognition, and apolipoprotein E genotype: latent class approach to identifying subtype. Am Geriatr Psychiatry 2009;17:344-52.

45. Blasko I, Kemmler G, Jungwirth S, et al. Plasma amyloid beta-42 independently predicts both late-onset depression and Alzheimer disease. Am J Geriatr Psychiatry 2010;18:973-82.

46. Metti AL, Cauley JA, Newman AB, et al. Plasma beta amyloid level and depression in older adults. J Gerontol A Biol Sci Med Sci 2013;68:74-9.

47. Sun X, Chiu CC, Liebson E, et al. Depression and plasma amyloid beta peptides in the elderly with and without the apolipoprotein E4 allele. Alzheimer Dis Assoc Disord 2009;23:238-44.

48. Szanto K, Clark L, Hallquist M, et al. The cost of social punishment and highlethality suicide attempts in the second half of life. Psychol Aging 2014;29: 84-94.

49. Schonknecht $\mathrm{P}$, Pantel J, Kaiser E, et al. Increased tau protein differentiates mild cognitive impairment from geriatric depression and predicts conversion to dementia. Neurosci Lett 2007;416:39-42.

50. Scogin F, Fairchild JK, Yon A, et al. Cognitive bibliotherapy and memory training for older adults with depressive symptoms. Aging Ment Health 2014;18:554-60.

51. Diniz BS, Teixeira AL, Machado-Vieira R, et al. Reduced serum nerve growth factor in patients with late-life depression. Am J Geriatr Psychiatry 2013;21: 493-6.

52. Diniz BS, Teixeira AL, Miranda AS, et al. Circulating glial-derived neurotrophic factor is reduced in late-life depression. J Psychiatr Res 2012;46:135-9.

53. Erickson KI, Miller DL, Roecklein KA. The aging hippocampus: interactions between exercise, depression, and BDNF. Neuroscientist 2012;18:82-97.

54. Arnold SE, Xie SX, Leung YY, et al. Plasma biomarkers of depressive symptoms in older adults. Transl Psychiatry 2012;3(2):e65.

55. Kohler S, Thomas AJ, Lloyd A, et al. White matter hyperintensities, cortisol levels, brain atrophy and continuing cognitive deficits in late-life depression. Br J Psychiatry 2010;196:143-9.

56. Sapolsky RM. Glucocorticoids and hippocampal atrophy in neuropsychiatric disorders. Arch Gen Psychiatry 2000;57:925-35.

57. Krishnan KR, Taylor WD, McQuoid DR, et al. Clinical characteristics of magnetic resonance imaging-defined subcortical ischemic depression. Biol Psychiatry 2004;55:390-7.

58. Taylor WD, Aizenstein HJ, Alexopoulos GS. The vascular depression hypothesis: mechanisms linking vascular disease with depression. Mol Psychiatry 2013;18: 963-74..

59. Taylor WD, McQuoid DR, Payne ME, et al. Hippocampus atrophy and the longitudinal course of late-life depression. Am J Geriatr Psychiatry 2014;22:1504-12. 
60. Lebedeva AK, Westman E, Borza T, et al. MRI-based classification models in prediction of mild cognitive impairment and dementia in late-life depression. Front Aging Neurosci 2017;2:913.

61. Xie C, Li W, Chen G, et al. The co-existence of geriatric depression and amnestic mild cognitive impairment detrimentally affect gray matter volumes: voxelbased morphometry study. Behav Brain Res 2012;235:244-50.

62. Zahodne LB, Gongvatana A, Cohen RA, et al. Are apathy and depression independently associated with longitudinal trajectories of cortical atrophy in mild cognitive impairment? Am J Geriatr Psychiatry 2013;21:1098-106.

63. Tadayonnejad R, Ajilore O. Brain network dysfunction in late-life depression: a literature review. J Geriatr Psychiatry Neurol 2014;27:5-12.

64. Butters MA, Klunk WE, Mathis CA, et al. Imaging Alzheimer pathology in late-life depression with PET and Pittsburgh compound-B. Alzheimer Dis Assoc Disord 2008;22:261-8.

65. Madsen K, Hasselbalch BJ, Frederiksen KS, et al. Lack of association between prior depressive episodes and cerebral [11C]PiB binding. Neurobiol Aging 2012;33:2334-42.

66. Kumar A, Kepe V, Barrio JR, et al. Protein binding in patients with late-life depression. Arch Gen Psychiatry 2011;68:1143-50.

67. Lavretsky H, Siddarth P, Kepe V, et al. Depression and anxiety symptoms are associated with cerebral FDDNP-PET binding in middle-aged and older nondemented adults. Am J Geriatr Psychiatry 2009; 17:493-502.

68. Chung JK, Plitman E, Nakajima S, et al. Lifetime history of depression predicts increased amyloid-B accumulation in patients with mild cognitive impairment. J Alzheimers Dis 2015;45(3):907-19.

69. Kohler S, Ashton CH, Marsh R, et al. Electrophysiological changes in late life depression and their relation to structural brain changes. Int Psychogeriatr 2011;23:141-8.

70. Katza R, De Sanctisa P, Mahoneya JR, et al. Cognitive control in late-life depression: response inhibition deficits and dysfunction of the anterior cingulate cortex. Am J Geriatr Psychiatry 2010;18:1017-25.

71. Lenze EJ, Sheffrin M, Driscoll HC, et al. Incomplete response in late-life depression: getting to remission. Dialogues Clin Neurosci 2008;10:419-30.

72. Cuijpers P, Karyotaki E, Pot AM, et al. Managing depression in older age: psychological interventions. Maturitas 2014;79(2):160-9.

73. Joosten-Weyn Banningh LW, Kessels RP, Olde Rikkert MG, et al. A cognitive behavioural group therapy for patients diagnosed with mild cognitive impairment and their significant others: feasibility and preliminary results. Clin Rehabil 2008;22:731-40.

74. Hollon SD, Ponniah K. A review of empirically supported psychological therapies for mood disorders in adults. Depress Anxiety 2010;27(10):891-932. 
75. Miller MD, Reynolds CF 3rd. Expanding the usefulness of interpersonal psychotherapy (IPT) for depressed elders with co-morbid cognitive impairment. Int J Geriatr Psychiatry 2007;22:1015 .

76. Bell AC, D'Zurilla TJ. Problem-solving therapy for depression: a meta-analysis. Clin Psychol Rev 2009;29(4):348-53.

77. Malouff JM, Thorsteinsson EB, Schutte NS. The efficacy of problem solving therapy in reducing mental and physical health problems: a meta-analysis. Clin Psychol Rev 2007;27(1):4657.

78. Alexopoulos GS, Raue PJ, Kiosse sDN, et al. Problem-solving therapy and supportive therapy in older adults with major depression and executive dysfunction: effect on disability. Arch Gen Psychiatry 2011;68:33-41.

79. Arean P, Hegel M, Vannoy S, et al. Effectiveness of problem-solving therapy for older, primary care patients with depression: results from the IMPACT project. Gerontologist 2008;48:311-23.

80. Arean PA, Raue P, Mackin RS, et al. Problem-solving therapy and supportive therapy in older adults with major depression and executive dysfunction. Am J Psychiatry 2010;167:1391-8.

81. Kiosses DN, Arean PA, Teri L, et al. Home-delivered problem adaptation therapy (PATH) for depressed, cognitively impaired, disabled elders: a preliminary study. Am J Geriatr Psychiatry 2010;18:988-98.

82. Bohlmeijer E, Smit F, Cuijpers P. Effects of reminiscence and life review on latelife depression: a meta-analysis. Int J Geriatr Psychiatry 2003;18(12):1088-94.

83. Pinquart M, Forstmeijer S. Effects of reminiscence interventions on psychosocial outcomes: a meta-analysis. Aging Ment Health 2012;16(5):541-58.

84. Ventegodt S, Merrick J. Meta-analysis of positive effects, side effects and adverse events of holistic mind-body medicine (clinical holistic medicine): experience from Denmark, Sweden, United Kingdom and Germany. Int J Adolesc Med Health 2009;21(4):441-56.

85. Mura G, Carta MG. Physical activity in depressed elderly: a systematic review. Clin Pract Epidemiol Ment Health 2013;9:125-35.

86. Blumenthal JA, Babyak MA, Moore KA, et al. Effects of exercise training on older patients with major depression. Arch Intern Med 1999;159(19):2349-56.

87. Bogner HR, Bruce ML, Reynolds CF 3rd, et al. The effects of memory, attention, and executive dysfunction on outcomes of depression in a primary care intervention trial: the PROSPECT study. Int J Geriatr Psychiatry 2007;22:922-9.

88. Mather AS, Rodriguez C, Guthrie MF, et al. Effects of exercise on depressive symptoms in older adults with poorly responsive depressive disorder: randomised controlled trial. Br J Psychiatry 2002;180:411-5. 
89. Northey JM, Cherbuin N, Pumpa KL, et al. Exercise interventions for cognitive function in adults older than 50: a systematic review with meta-analysis. Br J Sports Med 2017. [Epub ahead of print].

90. Mowszowski L, Hermens DF, Diamond K, et al. Cognitive training enhances preattentive neurophysiological responses in older adults "at risk" of dementia. J Alzheimers Dis 2014;41(4):1095-108.

91. Naismith SL, Diamond K, Carter PE, et al. Enhancing memory in late-life depression: the effects of a combined psychoeducation and cognitive training program. Am J Geriatr Psychiatry 2011;19:240-8.

92. Donker T, Batterham PJ, Warmerdam L, et al. Predictors and moderators of response to Internet-delivered interpersonal psychotherapy and cognitive behavior therapy for depression. $\mathrm{J}$ Affect Disord 2013;151:343-51.

93. Rosenberg D, Depp CA, Vahia IV, et al. Exergames for subsyndromal depression in older adults: a pilot study of a novel intervention. Am J Geriatr Psychiatry 2010;18:221-6.

94. Donker T, Petrie K, Proudfoot J, et al. Smartphones for smarter delivery of mental health programs: a systematic review. J Med Internet Res 2013;15:e247.

95. Nash JD, Newberg A. Toward a unifying taxonomy and definition for meditation. Front Psychol 2013;4:806.

96. Patel NK, Newstead AH, Ferrer RL. The effects of yoga on physical functioning and health related quality of life in older adults: a systematic review and metaanalysis. J Altern Complement Med 2012;18:902-17.

97. Lavretsky H, Alstein LL, Olmstead RE, et al. Complementary use of tai chi chih augments escitalopram treatment of geriatric depression: a randomized controlled trial. Am J Geriatr Psychiatry 2011;19:839-50.

98. Rogers CE, Larkey LK, Keller C. A review of clinical trials of tai chi and qigong in older adults. West J Nurs Res 2009;31:245-79.

99. Cross K, Flores R, Butterfield J, et al. The effect of passive listening versus active observation of music and dance performances on memory recognition and mild to moderate depression in cognitively impaired older adults. Psychol Rep 2012;111:413-23.

100. Hars M, Herrmann FR, Gold G, et al. Effect of music-based multitask training on cognition and mood in older adults. Age Ageing 2014;43:196-200.

101. McCaffrey R, Liehr P, Gregersen T, et al. Garden walking and art therapy for depression in older adults: a pilot study. Res Gerontol Nurs 2011;4:237-42.

102. Murrock CJ, Graor CH. The effects of dance on depression, physical function, and disability in underserved adults. J Aging Phys Act 2014;22(3):380-5.

103. Pehrson AL, Sanchez C. Serotonergic modulation of glutamate neurotransmission as a strategy for treating depression and cognitive dysfunction. CNS Spectr 2014;19:121-33. 
104. Murrough JW, Burdick KE, Levitch CF, et al. Neurocognitive effects of ketamine and association with antidepressant response in individuals with treatmentresistant depression: a randomized controlled trial. Neuropsychopharmacology 2015;40(5):1084-90.

105. Pimontel MA, Culang-Reinlieb ME, Morimoto SS, et al. Executive dysfunction and treatment response in late-life depression. Int J Geriatr Psychiatry 2012; 27:893-9.

106. Sneed JR, Culang ME, Keilp JG, et al. Antidepressant medication and executive dysfunction: a deleterious interaction in late-life depression. Am J Geriatr Psychiatry 2010;18:128-35.

107. Raskin J, Wiltse CG, Siegal A, et al. Efficacy of duloxetine on cognition, depression, and pain in elderly patients with major depressive disorder: an 8-week, double-blind, placebocontrolled trial. Am J Psychiatry 2007;164:900-9.

108. Wesnes K, Bose A, Gommoll C, Chen C. Effects of levomilnacipran SR on measures of attention in a phase 3 trial of major depressive disorder (MDD). Presented at NCDEU 53rdMeet., Am. Soc. Clin. Psychopharmacol., Hollywood, CA, May 28-31, 2013.

109. Khawam EA, Laurencic G, Malone DA. Side effects of antidepressants: an overview. Clevel Clin J Med 2006;73:351-3, 356-61.

110. Pelton GH, Harper OL, Tabert MH, et al. Randomized double-blind placebocontrolled donepezil augmentation in antidepressant-treated elderly patients with depression and cognitive impairment: a pilot study. Int J Geriatr Psychiatry 2008;23:670-6.

111. Reynolds CF 3rd, Butters MA, Lopez O, et al. Maintenance treatment of depression in old age: a randomized, double-blind, placebo-controlled evaluation of the efficacy and safety of donepezil combined with antidepressant pharmacotherapy. Arch Gen Psychiatry 2011;68:51-60.

112. Holtzheimer PE, Meeks TW, Kelley ME, et al. A double blind, placebo-controlled pilot study of galantamine augmentation of antidepressant treatment in older adults with major depression. Int J Geriatr Psychiatry 2008;23:625-31.

113. Lenze EJ, Skidmore ER, Begley AE, et al. Memantine for late-life depression and apathy after a disabling medical event: a 12-week, double-blind placebocontrolled pilot study. Int J Geriatr Psychiatry 2012;27:974-80.

114. Smith EG, Deligiannidis KM, Ulbricht CM, et al. Antidepressant augmentation using the Nmethyl-D-aspartate antagonist memantine: a randomized, doubleblind, placebo-controlled trial. J Clin Psychiatry 2013;74:966-73.

115. Zarate CA Jr, Singh JB, Quiroz JA, et al. A double-blind, placebo-controlled study of memantine in the treatment of major depression. Am J Psychiatry 2006;163:153-5.

116. Sackheim HA, Prudic J, Fuller R, et al. The cognitive effects of electroconvulsive therapy in community settings. Neuropsychopharmacology 2007;32:244-54.

117. Lisanby SH. Electroconvulsive therapy for depression. New Engl J Med 2007; 357:1939-45. 
118. Wahlund B, van Rosen D. ECT of major depressed patients in relation to biological and clinical variables: a brief overview. Neuropsychopharmacology 2003; 28(Suppl 1):S21-6.

119. McClintock SM, Choi J, Deng ZD, et al. Multifactorial determinants of the neurocognitive effects of electroconvulsive therapy. J ECT 2014;30:165-76.

120. Semkovska M, McLoughlin DM. Objective cognitive performance associated with electroconvulsive therapy for depression: a systematic review and metaanalysis. Biol Psychiatry 2010;68:568-77.

121. Sheline YI, Barch DM, Garcia K, et al. Cognitive function in late life depression: relationships to depression severity, cerebrovascular risk factors and processing speed. Biol Psychiatry 2006;60:58-65.

122. Ahmed MA, Darwish ES, Khedr EM, et al. Effects of low versus high frequencies of repetitive transcranial magnetic stimulation on cognitive function and cortical excitability in Alzheimer's dementia. J Neurol 2012;259:83-92.

123. Alexopoulos GS, Hoptman MJ, Kanellopoulos D, et al. Functional connectivity in the cognitive control network and the default mode network in late-life depression. J Affect Disord 2012;139:56-65.

124. Alexopoulos GS, Murphy CF, Gunning-Dixon FM, et al. Microstructural white matter abnormalities and remission of geriatric depression. Am J Psychiatry 2008;165:238-44.

125. Drevets WC, Price JL, Furey ML. Brain structural and functional abnormalities in mood disorders: implications for neurocircuitry models of depression. Brain Struct Funct 2008;213(12):93-118.

126. Dubois B, Litvan I. The FAB: a frontal assessment battery at bedside. Neurology 2000;55:1621-6.

127. Greicius MD, Flores BH, Menon V, et al. Resting-state functional connectivity in major depression: abnormally increased contributions from subgenual cingulate cortex and thalamus. Biol Psychiatry 2007;62(5):429-37.

128. Kennedy SH, Giacobbe P, Rizvi SJ, et al. Deep brain stimulation for treatmentresistant depression: follow-up after 3 to 6 years. Am J Psychiatry 2011;168(5): 502-10. 